\title{
Multiple Compound Foundation Bearing Characteristics
}

\author{
Zhou Cai-hui' ${ }^{1,}$, Chen $\mathrm{An}^{2, \mathrm{~b}}$ and Meng Jian ${ }^{3, \mathrm{c}}$ \\ ${ }^{1}$ Yunnan Geological Engineering Survey and Design Institute, KunMing 650093, China \\ ${ }^{2}$ KunMing University of Science and Technology, KunMing 650093, China \\ ${ }^{3}$ KunMing University of Science and Technology, KunMing 650093, China \\ a1010962171@qq.com, b373034075@qq.com, c850225075@qq.com
}

\begin{abstract}
Keywords: long rigid piles and short flexible piles, multiple compound foundations, bearing characteristics

Abstract. To study the bearing characteristics of composite foundation with long rigid piles and short flexible piles, the light dynamic penetration and the static loading test are used base on comprehensive testing and analysis of soft soil characteristics, and combining with the treatment design parameters of soft soil with long rigid piles and short flexible piles. The results show that it is feasible that using rigid piles with $400 \mathrm{~mm}$ diameter and $15 \mathrm{~m}$ length and flexible piles with $550 \mathrm{~mm}$ diameter and $6 \mathrm{~m}$ length to deal with soft soil mainly composed of flow plastic muddy clay. The composite foundation bearing capacity can reach $100 \mathrm{kPa}$, which meet the needs of the corresponding project.
\end{abstract}

\section{Introduction}

Soft soil has the characteristics of high natural water content, high compressibility and low bearing capacity, which cannot meet the requirements of the natural foundation. So it needs to be handled to improve its load-bearing. When using a variety of methods to jointly deal with the same soft ground, it has become a multi-composite foundation, such as long and short piles composite foundation, rigid and flexible pile composite foundation ${ }^{[1]}$. In fact, as early as the $1990 \mathrm{~s}$, people had the design idea of composite foundation and have made some research results. In 2001, Shi Xuguang was studied the performance of composite foundation with rigid-flexible composite piles by $3 \mathrm{D}$ elastic analysis ${ }^{[2]}$. In 2003, Guo Xinshen and Gong Xiaonan analyzed the performance of long-short pile composite foundation and explored the design method of long-short pile composite foundation and explored the design calculation method of long and short pile composite foundation by using the finite element method $^{[3]}$. In 2004, Shang Xinsheng discusses the working mechanism of multi-component composite foundation and its optimization design techniques ${ }^{[4]}$. In 2005, Lin Wenqiang and Xia Xuyang studied the stress-sharing of soft soil pile with rigid-flexible-pile composite foundation by testing $^{[5]}$. In 2012, Kong Dezhi and Lei Yanjie studied the relationship between load and settlement of rigid-flexible long-short pile composite foundation by model test ${ }^{[6]}$. However, most of the above research focuses on model tests or numerical simulation analysis, which does not involve the practical engineering applications of the length of rigid-flexible composite foundation. We rely on the Long-rigid piles and short-flexible piles are used to comprehensively treat soft-soil foundation projects of Ningbo Beilun port warehouse to test the composite foundation performance, which provide reference and reference for similar practical projects.

\section{Engineering geological conditions}

Ningbo Beilun port warehouse locate in northeast coastal region Beilun District, Ningbo City, Zhejiang Province. Project site is a coastal seaside plain. The ground level of the site is generally 1.76 $\sim 3.78 \mathrm{~m}$.

\section{Site stratum structure}

Site strata from top to bottom are as follows: 
(1)-1 Plain fill, it made of gravel and clay, the gravel particles are different sizes. The structure of the soil is loose. The soil is uneven, which distribution local area in engineering site. The thickness is $0.4-1.5 \mathrm{~m}$.

(1)-2 Silty clay, it is plastic state and its compressibility is medium compression to high compression. The soil is uneven, which distribution all engineering site. The thickness is $0.6-2.1 \mathrm{~m}$.

(2) Muddy clay, it is flow plastic state and its compressibility is high compression. The soil is uneven, which distribution all engineering site. The thickness is $11.6-17.4 \mathrm{~m}$.

(3) Silty clay, it is soft plastic to plastic state and its compressibility is medium compression. The soil is uneven, which distribution all engineering site. The thickness is $8.1-25.1 \mathrm{~m}$.

(4) Silty clay, it is soft plastic state and its compressibility is medium compression. The soil is uneven, which misses in local area. The thickness is $3.0-14.1 \mathrm{~m}$.

(5) Silty clay, it is flow plastic state and its compressibility is medium compression to low compression. The soil is uneven, which distribution all engineering site. There is a gravel in the soil, The thickness is more than $7.0 \mathrm{~m}$.

\section{Physical and mechanical properties}

The main physical and mechanical properties of each stratum in the site as shown in table 1 .

Table 1 Statistical table of physical and mechanical properties

\begin{tabular}{|c|c|c|c|c|c|c|}
\hline Stratum & $\begin{array}{l}\text { Statistical } \\
\text { indicators }\end{array}$ & $\begin{array}{c}\text { Water content } \\
\omega_{0}(\%) \\
\end{array}$ & $\begin{array}{c}\text { Porosity ratio } \\
\mathrm{e}\end{array}$ & $\begin{array}{c}\text { Cohesion } \\
\mathrm{C}(\mathrm{kPa})\end{array}$ & $\begin{array}{c}\text { Internal friction } \\
\text { angle } \Phi\left(^{\circ}\right) \\
\end{array}$ & $\begin{array}{l}\text { Compression } \\
\text { modulus } \mathrm{E}_{\mathrm{s} 1-2}\end{array}$ \\
\hline \multirow{3}{*}{$\begin{array}{l}\text { Silty clay } \\
\text { (1) }-2\end{array}$} & Range value & $24.6-42.0$ & $0.692-1.177$ & $16.1-38.8$ & $12.3-17.1$ & $2.91-6.80$ \\
\hline & average value & 31.0 & 0.869 & 26.8 & 14.6 & 4.83 \\
\hline & $\begin{array}{c}\text { Number of } \\
\text { samples }\end{array}$ & 53 & 53 & 50 & 50 & 53 \\
\hline \multirow{3}{*}{$\begin{array}{c}\text { Muddy } \\
\text { clay } \\
\text { (2) }\end{array}$} & Range value & $36.6-63.3$ & $1.027-1.748$ & $8.0-16.4$ & $7.0-12.9$ & $1.72-4.00$ \\
\hline & average value & 45.9 & 1.283 & 11.6 & 9.1 & 2.51 \\
\hline & $\begin{array}{l}\text { Number of } \\
\text { samples }\end{array}$ & 261 & 261 & 242 & 242 & 187 \\
\hline \multirow{3}{*}{$\begin{array}{l}\text { Silty clay } \\
\text { (3) }\end{array}$} & Range value & $21.0-40.6$ & $0.598-1.121$ & $17.3-58.0$ & $12.6-19.9$ & $3.95-8.88$ \\
\hline & average value & 29.3 & 0.821 & 31.6 & 15.6 & 5.53 \\
\hline & $\begin{array}{c}\text { Number of } \\
\text { samples }\end{array}$ & 312 & 312 & 312 & 312 & 128 \\
\hline \multirow{3}{*}{$\begin{array}{l}\text { Silty clay } \\
\text { (4) }\end{array}$} & Range value & $22.7-45.1$ & $0.664-1.276$ & $15.9-42.6$ & $12.2-20.7$ & $3.28-8.76$ \\
\hline & average value & 30.8 & 0.865 & 27.0 & 15.8 & 5.46 \\
\hline & $\begin{array}{c}\text { Number of } \\
\text { samples }\end{array}$ & 103 & 103 & 99 & 99 & 103 \\
\hline \multirow{3}{*}{ Silty clay } & Range value & $21.4-43.9$ & $0.611-1.257$ & $21.0-57.4$ & $13.7-18.7$ & $3.80-16.60$ \\
\hline & average value & 28.6 & 0.805 & 40.6 & 17.2 & 7.95 \\
\hline & $\begin{array}{c}\text { Number of } \\
\text { samples }\end{array}$ & 182 & 182 & 167 & 167 & 182 \\
\hline
\end{tabular}

\section{Hydrogeological conditions}

The site groundwater is mainly pore water, which mainly present in Plain fill (1)-1) and Silty clay (1) -2). The remaining of stratums are relative aquifers, which permeability is poor. The water content is poor. The water volume of the weak confined water under relative aquifers is not large. The dynamic change of water level is not obvious. The soil thickness above the weak confined water is large. The weak confined water has less impact on the project. 
The site groundwater depth is $0.40-1.20 \mathrm{~m}$, which altitude elevation is $1.81--2.40 \mathrm{~m}$. The main supply sources of site pore water are atmospheric precipitation and nearby surface water. The groundwater level during the wet period is higher and the groundwater level during the dry season is lower. The groundwater level change range is $0.50-1.00 \mathrm{~m}$.

\section{Natural foundation bearing capacity}

The bearing capacity of each stratum in the site, the stratum friction eigenvalues around pile $\left(q_{\mathrm{sa}}\right)$ and the stratum bearing capacity at the pile end $\left(q_{\mathrm{pa}}\right)$ as shown in table 2 .

Table 2 The bearing capacity of each stratum

\begin{tabular}{|c|c|c|c|c|c|c|c|}
\hline \multirow{2}{*}{ Stratum } & \multirow{2}{*}{$\begin{array}{c}\text { Bearing capacity } \\
\qquad f_{a k} \mathrm{kPa}\end{array}$} & \multicolumn{2}{|c|}{$\begin{array}{l}\text { Prefabricated concrete } \\
\text { pipe pile }\end{array}$} & \multicolumn{2}{|c|}{ Drilling piles } & \multirow{2}{*}{$\begin{array}{l}\text { Cement and } \\
\text { soil mixing pile } \\
\qquad f \mathrm{kPa}\end{array}$} & \multirow{2}{*}{$\begin{array}{c}\text { Uplift } \\
\text { factor } \\
\lambda_{i}\end{array}$} \\
\hline & & $q_{\text {sia }} \mathrm{kPa}$ & $q_{p a} \mathrm{kPa}$ & $q_{\text {sia }} \mathrm{kPa}$ & $q_{p a} \mathrm{kPa}$ & & \\
\hline Silty clay (1)-2 & 60 & 6 & & 5 & & 12 & 0.65 \\
\hline Muddy clay (2) & 30 & 4 & & 3 & & 7 & 0.50 \\
\hline Silty clay (3) & 80 & 8 & 200 & 7 & 150 & 22 & 0.65 \\
\hline Silty clay (4) & 70 & 7 & 150 & 6 & 120 & & 0.65 \\
\hline Silty clay (5) & 90 & 9 & 220 & 8 & 160 & & 0.70 \\
\hline
\end{tabular}

\section{Multiple compound foundations of long rigid piles and short flexible piles}

The processing area is the planned warehouse area. Warehouse estimated maximum load is approximately $400 \mathrm{kN} /$ column, which requires that the composite foundation bearing capacity $\left(\mathrm{f}_{\text {spk }}\right)$ after reinforcement in the warehouse area is more than $100 \mathrm{kPa}$. The maximum ground load is $50 \mathrm{kN} / \mathrm{m}^{2}$, which allowable settlement is less than $30 \mathrm{~mm}$. In order to achieve the above capacity and settlement requirements, long rigid piles and short flexible piles are used to deal with the soft ground of the site. Details are as follows:

The long rigid piles are $400 \mathrm{~mm}$ diameter prestressed concrete pipe pile, which length is $15 \mathrm{~m}$. The pile spacing is $3600 \mathrm{~mm}(\mathrm{~N}-\mathrm{S}) \times 3400 \mathrm{~mm}(\mathrm{E}-\mathrm{W})$. The short flexible piles are cement and soil mixing piles, which length is $6 \mathrm{~m}$ with $550 \mathrm{~mm}$ diameter. The pile spacing is $1800 \mathrm{~mm}(\mathrm{~N}-\mathrm{S})$ $\times 1700 \mathrm{~mm}(\mathrm{E}-\mathrm{W})$, which will be cancelled If it overlaps with the position of the long pile. The cement content of the short flexible piles is not less than $15 \%$.

\section{Composite foundation bearing capacity inspect}

\section{Light Cone Penetration Test}

The light cone penetration test are implemented at 27 points (avoid rigid piles) in composite foundation which after being processed for 3 days. The results of the lightweight penetration test are shown in Table 3.

The lightweight penetration test results corresponding to the bearing capacity of the foundation can be calculated using formula (1).

$$
\mathrm{R}=\left(0.8 \times \mathrm{N}_{10}-2\right) \times 9.8
$$

$\mathrm{R}$ - the bearing capacity of the foundation, $\mathrm{N}_{10}$-hammer number of light cone penetration test. The calculation results are shown in Table 3.

Table 3 Light penetrating test results correspond to foundation bearing capacity $(\mathrm{kPa})$

\begin{tabular}{|c|c|c|c|c|c|c|c|c|}
\hline Depth (m) & $0.0-0.3$ & $0.5-0.8$ & $1.0-1.3$ & $1.5-1.8$ & $2.0-2.3$ & $2.5-2.8$ & $3.0-3.3$ & $3.5-3.8$ \\
\hline $\mathrm{N}_{10}$ & 18 & 18 & 19 & 19 & 20 & 20 & 22 & 25 \\
\hline $\begin{array}{c}\text { Bearing } \\
\text { capacity }\end{array}$ & 122 & 122 & 129 & 129 & 137 & 137 & 153 & 176 \\
\hline
\end{tabular}




\section{Static load test}

The static load test are implemented at 4 points (avoid rigid piles) in composite foundation which after being processed for 30 days. The square load plate is $1 \mathrm{~m} \times 1 \mathrm{~m}$. The test grading loading is $20 \mathrm{kPa}$. The first stage load is $40 \mathrm{kPa}$ and the last stage load is $200 \mathrm{kPa}$.

The results of the static load test are shown as figure 1 .
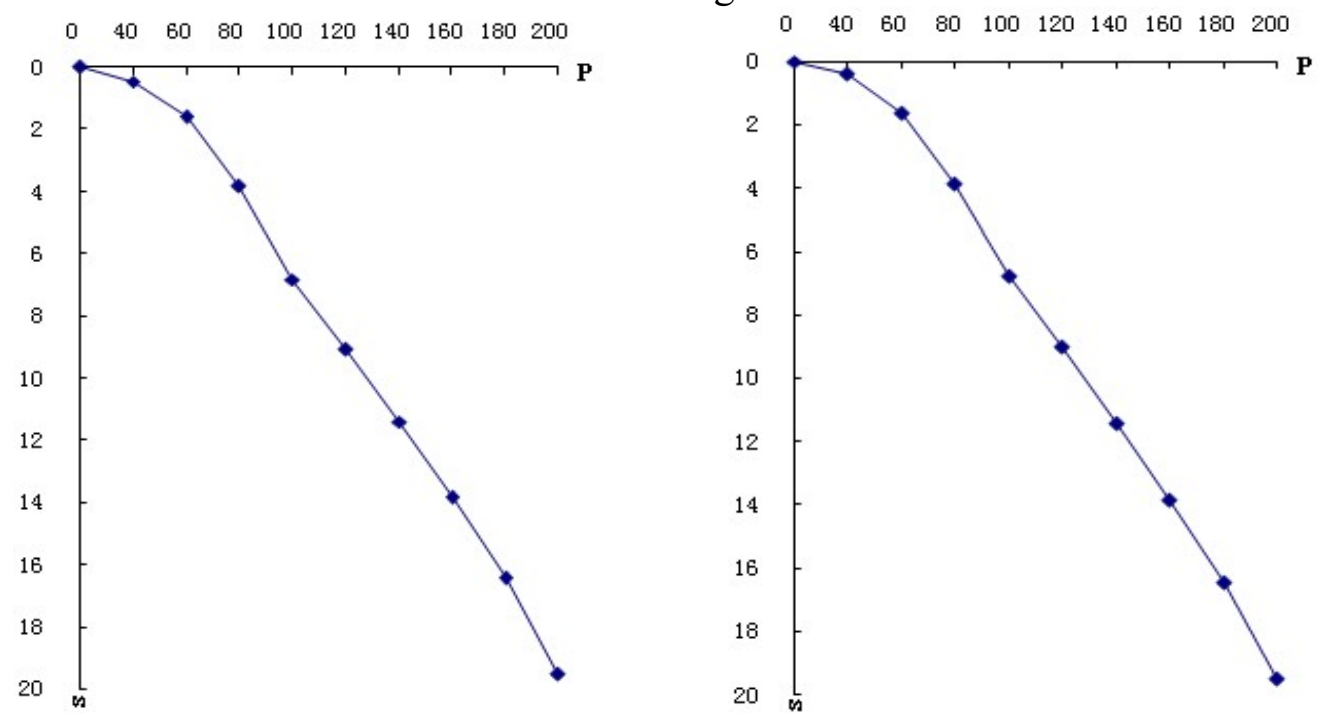

No. 1 Test spot

No. 2 Test spot

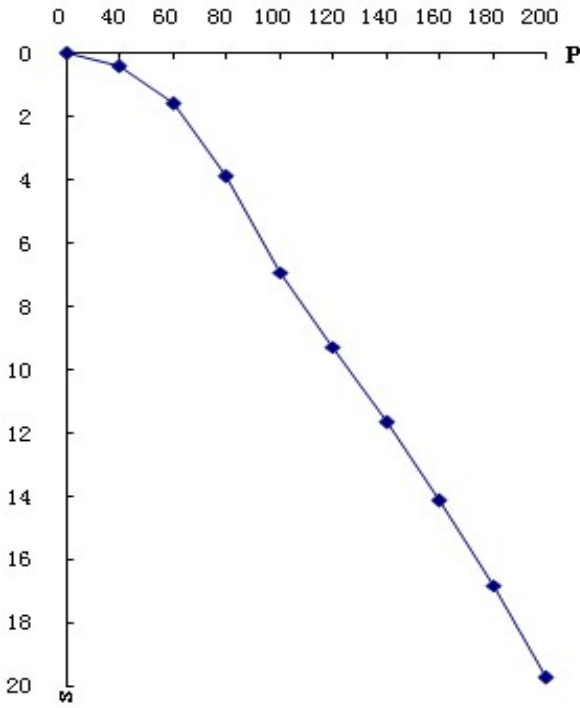

No. 3 Test spot

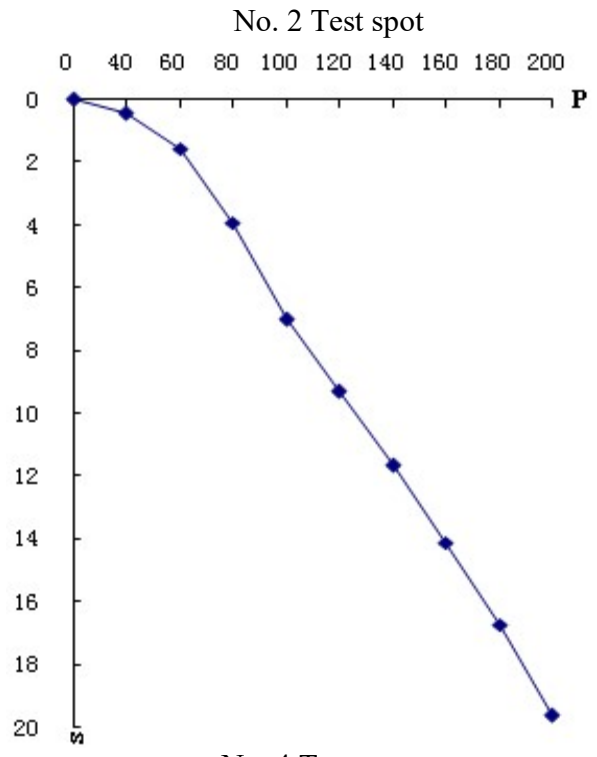

No. 4 Test spot

Fig. 1 Composite ground static load test results

\section{Conclusions}

(1) It is feasible for using long- rigid and short-flexible piles to deal with soft ground composed mainly of muddy clays with plastic flow state and silty clays with soft plastics and plastics state.

(2) The long piles are rigid piles with $400 \mathrm{~mm}$ diameter, which length is $15 \mathrm{~m}$. The pile spacing is $3600 \mathrm{~mm}(\mathrm{~N}-\mathrm{S}) \times 3400 \mathrm{~mm}(\mathrm{E}-\mathrm{W})$. The short piles are flexible piles with cement and soil mixing piles, which length is $6 \mathrm{~m}$ with $550 \mathrm{~mm}$ diameter. The pile spacing is $1800 \mathrm{~mm}(\mathrm{~N}-\mathrm{S}) \times 1700 \mathrm{~mm}(\mathrm{E}-\mathrm{W})$ (3) The hammer number of light cone penetration test is 18 to 25 , which corresponding bearing capacity is $120 \mathrm{Kpa}$ to $170 \mathrm{Kpa}$

(4)The static load test results show that the bearing capacity is about $110 \mathrm{Kpa}$, which is basically consistent with light cone penetration test results. It meets the requirements of the corresponding project 


\section{References}

[1] Gong Xiao-nan. Composite foundation theory and engineering application[M]. BeiJing: China Architecture \& Building Press, 2007

[2] Shi Xu-guang. Three-dimensional Elastic Analysis of Composite Foundation Characteristics of Rigid and Flexible Columns[D]. HangZhou: Zhejiang University, 2001)

[3] GE Xinsheng, GONG Xiaonam, ZHANg Xianming. FEM analysis and design of long-short-pile composite foundation[J]. Journal of Building Structures, 2003, 24 (4): 91-96

[4] Shang Xin-sheng. Research on Working Mechanism and Optimization Design of Multi-element Composite Foundation[D]. XiAn: Xi'an University of Technology, 2004

[5] LIN Wen-qiang, XIA Xu-yang, CHEN Yan-meng. Experimental Research on Pile-Soil Stress Comparison in Soft Soil Subgrade Consolidation with Composite Foundation of Rigid\&Flexible Piles[J]. Port \& Waterway Engineering, 2005, 378 (7): 37-41

[6] Kong De-zhi, Lei Yan-jie, Wei Jun-jun. Study by Complex for Ground Constituted of Different Rigid and Length Pile[J]. Journal of Henan University(Natural Science), 2012，42(5): 654-657

[7] Metallurgical Industry Ministry of Construction Research Institute. YBJ225-91 Technical Regulations of Deep Stirring and Stabilizing Method for Soft Soil Foundation[S]. BeiJing: Metallurgical Industry Press, 1991

[8] China Communications First Navigation Engineering Bureau, CCCC First Navigation Engineering Survey and Design Institute. JTJ/T 259-2004 Technical Regulations for Reinforcing Soft Soil Foundation by Underwater Deep Layer Cement Mixing[S]. BeiJing: China Communications Press, 2004 